\title{
Transfer of a lumen-apposing metal stent to a different fistula for endoscopic necrosectomy of walled-off pancreatic necrosis
}
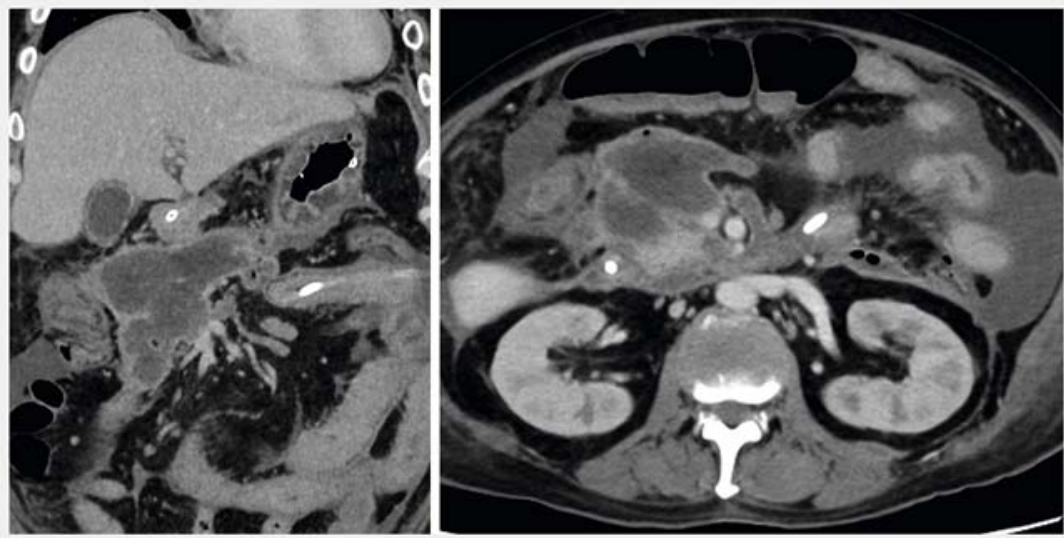

Fig. 1 Computed tomography showing walled-off necrosis extended toward the right pelvic cavity.
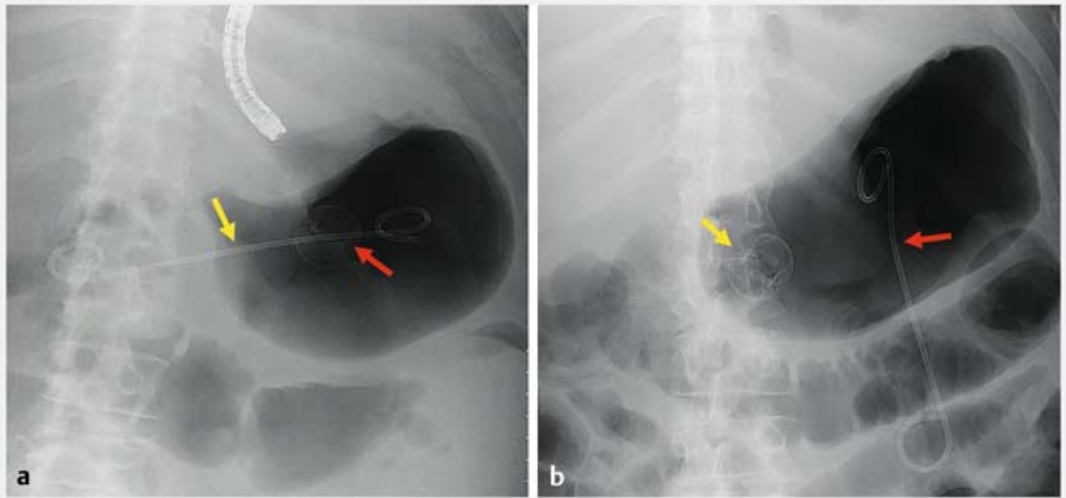

- Fig. 3 X-ray before (a) and after stent transfer (b). The lumen-apposing metal stent was transferred from the body fistula (red arrow) to the antrum fistula (yellow arrow), and the plastic stent was transferred from the antrum fistula (yellow arrow) to the body fistula (red arrow).

A 54-year-old man underwent multiple rounds of endoscopic necrosectomy via a 15-mm-diameter lumen-apposing metal stent (LAMS) (Hot AXIOS; Boston Scientific, Marlborough, MA, USA) in the gastric body for a large walled-off pancreatic necrosis (WON); however, infectious WON remained ( $\mathbf{F i g} \mathbf{\text { 1) }}$ ). Endoscopic ultrasound-guided transmural drainage with a plastic stent through the antrum was performed. Because of the unstable position of the echoendoscope, a LAMS was not used. Endoscopic necrosectomy was attempted 6 days later, but scope insertion through the antrum fistula was difficult. Thus, we attempted to transfer the LAMS from the gastric body to the antrum fistula.

The distal flange of the LAMS removed from the gastric body was grasped with

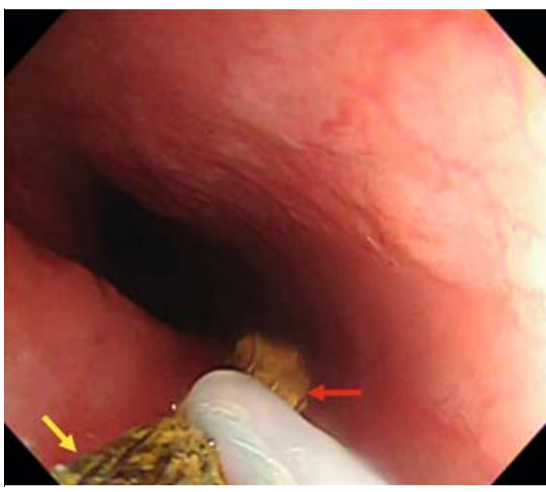

-Fig. 2 Endoscopic image of the esophagus before replacement of the lumen-apposing metal stent showing the distal flange of the stent grasped with a snare forceps (red arrow) through the right channel of a two-channel endoscope and the proximal flange inserted into the other channel (yellow arrow).

20-mm snare forceps through one channel of a two-channel endoscope. The manually compressed proximal flange was retrogradely inserted into the other channel ( $\triangleright$ Fig.2). The scope was inserted into the WON, and the distal flange was released into the cavity first. Next, the scope was gradually withdrawn, and an attempt was made to push the LAMS using forceps to release the proximal flange into the gastric lumen. However, the proximal flange was unintentionally released into the WON. A conventional endoscope was then inserted into the WON, and the proximal flange was successfully withdrawn into the gastric lumen by grasping the proximal flange with forceps. The LAMS placement facilitated smooth scope insertion into the WON. Finally, for fistula maintenance, the plastic stent removed from the antrum fistula was redeployed to the body fistula ( $>$ Fig. 3, > Video 1).

Although the removal and replacement of the same LAMS have been reported recently [1-3], there have been no reports of LAMS transfer to another fistula for endoscopic necrosectomy. This case 


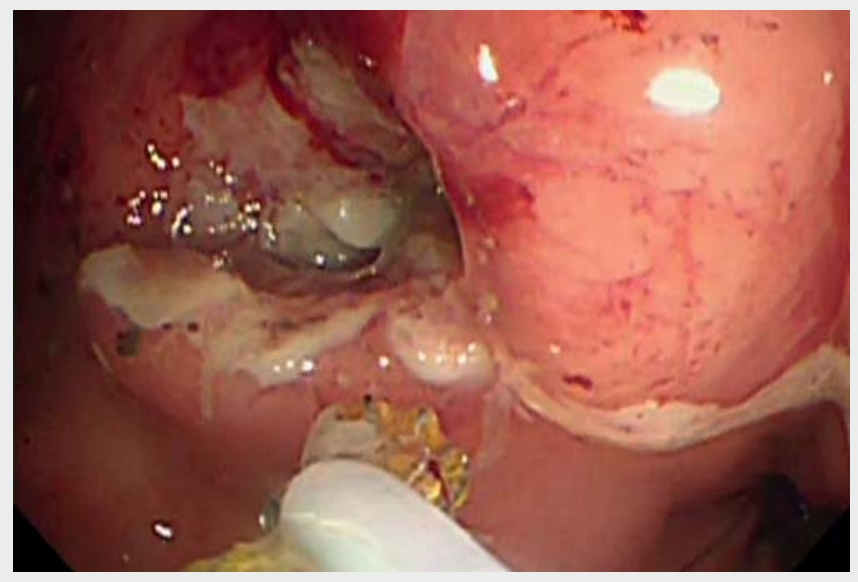

$\checkmark$ Video 1 Deployment of a lumen-apposing metal stent to a different fistula using a twochannel endoscope.

suggests that endoscopic necrosectomy from multiple fistulas with a single LAMS is possible by transferring the LAMS to another fistula with placement of a plastic stent.

\section{Endoscopy_UCTN_Code_CPL_1AL_2AD}

\section{Competing interests}

The authors declare that they have no conflict of interest.

The authors

\section{Koichiro Mandai ${ }^{\ominus}$, Tetsuhisa Ko, Koji Uno, Kenjiro Yasuda}

Department of Gastroenterology, Kyoto Second Red Cross Hospital, Kyoto, Japan

\section{Corresponding author}

\section{Koichiro Mandai, MD}

Department of Gastroenterology, Kyoto Second Red Cross Hospital, 355-5 Haruobicho, Kamigyo-ku, Kyoto 602-8026, Japan mndkchr@gmail.com

\section{References}

[1] Guarner AC, Colán-Hernández ], Concepción-Martín M et al. Replacement of the same lumen-apposing metallic stent for multiple necrosectomy sessions. Endoscopy 2015; 47: E447-E448

[2] Yoshida M, Naitoh I, Yamada R et al. On-andoff deployment technique of a lumen-apposing metal stent during endoscopic pancreatic necrosectomy. Endoscopy 2020; 52: E158-E159
[3] Gulati R, Rustagi T. Endoscopic removal and replacement of the same lumen-apposing metal stent for multiple endoscopic necrosectomy sessions (with video). Endoscopy 2020. doi:10.1055/a-1192-3219

Bibliography

Endoscopy 2021; 53: E429-E430

DOI $10.1055 / \mathrm{a}-1327-1993$

ISSN 0013-726X

published online 27.1.2021

(c) 2021. Thieme. All rights reserved.

Georg Thieme Verlag KG, Rüdigerstraße 14, 70469 Stuttgart, Germany

\section{ENDOSCOPY E-VIDEOS \\ https://eref.thieme.de/e-videos}

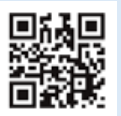

Endoscopy E-Videos is a free access online section, reporting on interesting cases and new techniques in gastroenterological endoscopy. All papers include a high quality video and all contributions are freely accessible online.

This section has its own submission website at

https://mc.manuscriptcentral.com/e-videos 